\title{
Efecto In Vitro de las Bebidas Refrescantes sobre la Mineralización de la Superficie del Esmalte Dentario de Piezas Permanentes Extraídas
}

\author{
In Vitro Effect of Refreshing Drinks on the Mineralization of \\ Tooth Enamel Surface in Extracted Permanent Dental Pieces
}

Ximena Moreno Ruiz*; Carmen Gloria Narváez Carrasco* \& Verónica Bittner Schmidt ${ }^{\star * *}$

MORENO R. X.; NARVÁEZ, C. C. G. \& BITTNER, S. V. Efecto in vitro de las bebidas refrescantes sobre la mineralización de la superficie del esmalte dentario de piezas permanentes extraídas. Int. J. Odontostomat., 5(2):157-163, 2011.

RESUMEN: El objetivo de este estudio fue determinar el efecto de las bebidas refrescantes sobre la mineralización de la superficie del esmalte de piezas dentarias permanentes extraídas. Para esto se realizó un estudio experimental donde la muestra correspondió a 50 cortes de premolares permanentes extraídos en estado íntegro, estos fueron distribuidos en tres grupos de estudio mediante asignación aleatoria: bebidas gaseosas, jugos y néctares, y aguas minerales purificadas y saborizadas más un grupo control. Los dientes fueron lavados y almacenados en saliva artificial a $4^{\circ} \mathrm{C}$. A todos los cortes dentarios se les midió la mineralización con el equipo Diagnodent 2095 (Kavo®) antes de iniciar la exposición, la cual correspondió a un minuto en el tipo de bebida según grupo, seguido por tres minutos en saliva artificial, ciclo que se repitió cinco veces en un tiempo de 20 minutos. Este procedimiento se realizó una vez al día, por un mes y para cada día se utilizaron nuevas bebidas refrescantes. Una vez finalizado se volvió a medir la mineralización para luego realizar las comparaciones entre grupos. El grupo de bebidas gaseosas provocó una mayor desmineralización en la superficie del esmalte dentario $(p=0,000)$, seguido del grupo de jugos y néctares $(p=0,000)$. El grupo de aguas minerales saborizadas y purificadas no provocaron efectos sobre la mineralización de la superficie del esmalte. Por lo tanto, sólo el grupo de gaseosas y jugos provocaron un efecto desmineralizador en la superficie del esmalte de las piezas dentarias, siendo la Coca-cola $₫$ la que produjo mayor efecto seguido de la Coca-cola light@ y luego el Kapo®.

PALABRAS CLAVE: erosión, esmalte, mineralización, desmineralización, bebidas refrescantes, diagnodent.

\section{INTRODUCCIÓN}

El presente estudio se ha enfocado en determinar el efecto in vitro que provocan las distintas bebidas refrescantes sobre la mineralización de piezas permanentes extraídas, para esto se realizó un estudio experimental con el objetivo de determinar si existen diferencias entre cada uno de los grupos de las bebidas refrescantes. Durante años, la Asociación Dental Americana ha recomendado que los niños y los adultos limiten el consumo de alimentos y bebidas entre comidas ya que, de acuerdo con los estudios publicados, hay una asociación positiva entre el alto consumo de refrescos con azúcar y el riesgo de desarrollar caries dentales. Además, se ha observado que la ex- posición prolongada a los ácidos de algunos alimentos puede generar un daño permanente a los dientes al producir la condición de "erosión" (JADA, 2002).

Las bebidas son líquidos usados generalmente para satisfacer la sed y el efecto erosivo de una bebida depende no sólo de su potencial erosivo, sino de las características individuales del paciente: capacidad buffer y rango flujo salival, al igual que la formación de la película adquirida. "La mayoría de las bebidas contienen uno o más acidulantes, los más comunes son ácido fosfórico y ácido cítrico, pero también pueden presentar ácido maleico, tartárico, entre otros" (López \&

\footnotetext{
* Cirujano Dentista. Facultad de Odontología, Universidad del Desarrollo, Concepción, Chile.

${ }^{* *}$ Bioquímico. Magister en educación superior. Docente facultad de Odontología, Universidad del Desarrollo, Concepción, Chile.

${ }^{* * *}$ Estadístico. Docente facultad de Odontología, Universidad del Desarrollo, Concepción, Chile.
} 
Cerezo, 2008). La cantidad y características de los ácidos adicionados a los distintos refrescos determinan el sabor y la calidad de éstas (Mas, 2002). Sin embargo, algunos pueden actuar como agente quelante, capaz de captar los minerales (calcio) del esmalte o la dentina, aumentando así el grado de infrasaturación y favoreciendo una mayor desmineralización, como es el caso del ácido cítrico (Zero \& Lussi, 2005). Las bebidas gaseosas dietéticas simplemente cambian el azúcar por edulcorantes no nutritivos que son generadores de ácidos y que también pueden provocar riesgo de erosiones en el esmalte. "Observaciones clínicas sugieren que el tiempo en que el diente es bañado en un ambiente ácido tiene mayor impacto que el volumen del bebestible consumido" (Carvalho et al., 2007).

En el año 2000, el consumo de bebidas incluyendo colas, bebidas deportivas y jugos de frutas aumentó en un $500 \%$ en Estados Unidos comparado hace 50 años atrás (Owens \& Kitchens, 2007), ya en el 2007, el consumo mundial de refrescos alcanzó los 552.000 millones de litros, el equivalente a casi 83 litros por persona y año, y se espera que llegue hasta los 95 litros por persona al año 2012 (SINC, 2009). A nivel mundial, Chile es uno de los tres países con mayor consumo per cápita de bebidas refrescantes, luego de EEUU y México. En el 2009, las empresas asociadas a Anber (Asociación Nacional de Bebidas Refrescantes), vendieron en volumen 2195 millones de litros dentro del país, obteniendo como promedio 26 litros al mes por familia. En el primer semestre del año 2010 las ventas ascendieron a un total de 1121 millones de litros. Para los chilenos las bebidas son el tercer producto en importancia de los 160 productos que componen la canasta de alimentos, siendo superadas sólo por bienes de consumo básico como la carne y el pan (www.anber.cl).

El esmalte dentario es el tejido que se encuentra recubriendo la corona anatómica de las piezas dentarias y su espesor varía desde 2 a $2,5 \mathrm{~mm}$, está constituido químicamente por una matriz orgánica $(2 \%)$, una matriz inorgánica $(95 \%)$ y agua (3\%). El componente orgánico más importante es de naturaleza proteica. La matriz inorgánica está constituida por sales minerales cálcicas, básicamente fosfatos, las cuales dan origen a los cristales de hidroxiapatita y otras sales minerales en menor proporción. Estos cristales de hidroxiapatita son susceptibles a la acción de los ácidos constituyendo esta característica el sustrato químico que da origen a las caries y ero- sión dental (Mas). La desmineralización se produce cuando la acidez se sitúa por debajo del pH 5.5 que es el $\mathrm{pH}$ crítico de la hidroxiapatita, de esta forma se producirá una liberación de iones de calcio y fosfato desde el esmalte hacia el medio circundante (Featherstone et al., 1993) provocando erosión en las piezas dentarias, éste término deriva del latín erodere, erosi, erosum (corroer) el cual describe el proceso de destrucción gradual de la superficie de un cuerpo, generalmente por procesos electrolíticos o químicos (Liñan et al., 2007), no incluyendo la participación de microorganismos de la flora bacteriana intraoral (Narváez, 2008). En los últimos años ha existido un gran incremento en la prevalencia de la erosión dental, sobretodo en la población de niños y adolescentes, siendo uno de los factores de riesgo más importante la ingesta de bebidas carbonatadas (Liñan et al.), bebidas ácidas, light, deportivas y jugos de frutas (Zero \&Lussi).

De aquí la importancia de entregar un nuevo conocimiento sobre el efecto que pueden producir estos tipos de bebidas resfrescantes a nivel dentario en consumidores habituales de éstos. Los principales son niños y jóvenes los cuales no poseen conocimiento sobre los efectos a largo plazo de éstos refrescos y los posibles daños a los que se exponen.

\section{MATERIAL Y MÉTODO}

El diseño de la investigación es de tipo experimental. La muestra correspondió a 25 premolares permanentes extraídos en estado íntegro (sin caries, restauraciones ni defectos del esmalte). Los dientes se cortaron por la mitad con discos carburundum, obteniendo un total de 50 muestras. Luego fueron lavados con cepillos dentales y agua destilada y posteriormente con escobillas profilácticas y agua destilada con el fin de remover los restos de sangre, tejido periodontal y pulpar. A todos los dientes recolectados se les midió la mineralización con la punta B del equipo Diagnodent 2095 (Kavo®) previa calibración y se seleccionaron los dientes que presentaron valores de mineralización entre 2 y 3 , descartándose los demás. Este equipo mide la fluorescencia emitida a través del esmalte y arroja valores que van de 0 a 99, donde 0 corresponde a cantidad adecuada de minerales y 99 ausencia de minerales, por lo tanto mientras mayor sea el valor registrado menor mineralización en el esmalte dentario. Una vez obtenida la muestra requerida, los 50 trozos de dientes 
se asignaron aleatoriamente en cuatro grupos: tres grupos de estudio con 15 cortes para cada uno y un grupo control con 5 cortes de premolares. Grupo A (bebidas refrescantes), grupo B (jugos y néctares), grupo $C$ (aguas minerales purificadas y saborizadas) y grupo D (control). Posteriormente, los cortes dentarios de cada grupo de estudio se subdividieron aleatoriamente en tres subgrupos de 5 cortes dentarios cada uno, en el grupo $A$ Coca-Cola $\AA$, Coca-cola light $₫$ y Fanta $\circledast$; en el grupo B Watts $®$, Andina ${ }^{\circledR}$ y Kapo ${ }^{\circledR}$ sabor manzana y en el grupo $C$ Benedictino $\AA$, Vital $₫$ y Cachantun sabor limón $\circledast$, las bebidas refrescantes fueron elegidas de acuerdo al consumo en la ciudad de Concepción, Chile. En los grupos de estudio los dientes serán sometidos a la acción de bebidas refrescantes mientras que el grupo control se someterá a saliva artificial.

Los dientes se mantuvieron en todo momento en refrigeración a $4^{\circ} \mathrm{C}$ en saliva artificial preparada en el Laboratorio de Investigación de la Universidad del Desarrollo de Concepción, según la siguiente fórmula:

- 9.8 bicarbonato de sodio $\left(\mathrm{NaHCO}_{3}\right.$ ); 7.0 Fosfato ácido de sodio heptahidratado $\left(\mathrm{Na}_{2} \mathrm{HPO}_{4} 7 \mathrm{H}_{2} \mathrm{O}\right) ; 0.57$ Cloruro de potasio ( $\mathrm{KCL}$ ); 0.47 Cloruro de sodio $(\mathrm{NaCl}) ; 0.04$ Cloruro de calcio $\left(\mathrm{CaCl}_{2}\right) ; 0.12$ Sulfato de magnesio $\left(\mathrm{MgSO}_{4} 7 \mathrm{H}_{2} \mathrm{O}\right)$.

Cada compuesto de la fórmula se mezcló con $1 \mathrm{~L}$ de agua destilada mediante un shaker en un frasco de vidrio con tapa de $1000 \mathrm{cc}$. Esta saliva se mantuvo refrigerada $a^{\circ} \mathrm{C}$, para evitar el crecimiento de bacterias ambientales que pudieran provocar alteraciones en la solución. Se preparó saliva cada vez que fue necesario. Las bebidas refrescantes también fueron mantenidas en refrigeración a $4^{\circ} \mathrm{C}$ hasta el momento de ocuparlas.

Para comenzar el procedimiento, cada uno de los trozos de premolares seleccionados fue numerado y se marcó con lápiz permanente la zona a medir con el equipo Diagnodent 2095 (Kavo®). A todos los cortes se les realizaron 3 mediciones iniciales, para sacar un promedio y disminuir el error. A cada bebida refrescante se le midió 5 veces el $\mathrm{pH}$ a lo largo de todo el ciclo experimental, al igual que a la saliva artificial preparada, utilizando pHmetro WP-90 lon/ $\mathrm{pH} / \mathrm{mV}$-Temp (TPS $\AA$ ), previa calibración. Se depositaron $30 \mathrm{ml}$ de cada bebida refrescante en vasos precipitados de $50 \mathrm{ml}$ y $20 \mathrm{~mL}$ de saliva artificial en vasos precipitados de $25 \mathrm{ml}$. Los dientes seleccionados para cada subgrupo se depositaron con una pin- za metálica biangulada en vasos precipitados rotulados y fueron expuestos por 1 minuto a la acción de las bebidas gaseosas, jugos y néctares, aguas minerales según correspondió, seguido por tres minutos en saliva artificial. Este ciclo se repitió cinco veces en 20 minutos para simular los hábitos actuales de consumo de bebidas, el grupo control se mantuvo constantemente en saliva artificial. Finalmente, se procedió a lavar los dientes en agua destilada y se almacenaron según grupo en saliva artificial. La saliva artificial en la que se almacenaban fue cambiada cada 7 días para asegurar sus propiedades. Este procedimiento se realizó una vez al día durante 1 mes y para cada día del experimento se utilizaron bebidas refrescantes nuevas para garantizar sus propiedades (Liñan et al., 2007). Una vez finalizado dicho procedimiento, se retiraron las muestras por grupo, se secaron con gasa y se midió 3 veces la mineralización con el equipo Diagnodent 2095 (Kavo®) para obtener la mineralización final de éstas.

Antes de cada lectura con el equipo Diagnodent 2095 (Kavo®), el instrumento fue calibrado y se determinó de esta forma el valor de fluorescencia del esmalte sano para cada pieza dentaria con el fin de obtener un valor base de cada diente. La calibración del operador respecto al pHmetro se efectuó al realizar las mediciones de calibración del equipo, en cuanto al Diagnodent 2095 (Kavo®) se realizó una calibración intraoperador e interoperador de 2 sujetos con 3 mediciones por cada muestra.

Además se midió la capacidad tampón de cada una de las bebidas refrescantes. Para esto, en un tubo de ensayo se puso $1 \mathrm{ml}$ de cada bebida y se midió el pH inicial, luego se agregaron $3 \mathrm{ml}$ de $\mathrm{HCL}$ $0.005 \%$ en cada uno de los tubos de ensayos y se esperó 20 minutos para posteriormente medir el pH y compararlo con la medición inicial y de esta forma determinar la capacidad tampón de cada una de las bebidas. Este procedimiento se realizó tres veces para verificar cada una de las mediciones.

Los datos fueron traspasados a una base de datos Excel y posteriormente se realizaron los análisis con el programa SPSS 11.5 para Windows. Como medidas descriptivas se utilizaron la media aritmética y las desviación estándar. Con el fin de comparar los valores medios de los grupos de estudios se utilizó un análisis de varianza jerarquizado y para comparar los efectos dentro de cada grupo un análisis de varianza simple y comparaciones múltiples de Scheffé. 


\section{RESULTADOS}

La Tabla I muestra el pH de cada unas de las bebidas refrescantes así como la capacidad tampón de cada una de ellas, siendo la bebida de menor $\mathrm{pH}$ la Coca-cola ${ }^{\circledR}$ y la que presentó una mayor capacidad tampón. En el grupo A de bebidas gaseosas, la bebida gaseosa que provocó mayor desmineralización fue la Coca-cola $₫$, seguida de la Coca-cola light $₫$, no existiendo diferencias significativas entre estas dos bebidas $(p=0,447)$, si se encontraron diferencias significativas entre la Coca-cola $₫$ y Fanta $₫(p=0,000)$ y la Cocacola light ${ }^{\circledR}$ y Fanta ${ }^{\circledR}(p=0,002)$. En el grupo $B$ de jugos y néctares, el Kapo® fue el que provocó mayor grado de desmineralización, encontrándose sólo diferencias significativas entre el Kapo® y Andina $₫$ manzana $(p=0,038)$, no se encontraron diferencias significativas entre el jugo Watts ${ }^{\circledR}$ de manzana y Andina ${ }^{\circledR}$ $(p=0,792)$ ni entre Watts de manzana con el Kapo® manzana $(p=0,120)$. El grupo $C$ de aguas minerales saborizadas y purificadas no registró cambios signifi- cativos en la mineralización de la superficie del esmalte, $y$ tampoco hubo diferencias significativas entre cada uno de ellas $(p=0,599)$.

La Tabla II muestra la mineralización inicial y final medida con el equipo Diagnodent (Kavo®) y la diferencia entre ellas. Se encontraron diferencias significativas entre el efecto que provocaron los grupos A, B, C y control $(p=0,000)$. La figura 1 , muestra la diferencia de mineralizaciones según grupo de bebida refrescante. El grupo A fue el que produjo mayor desmineralización promedio en la superficie del esmalte dentario, seguido del grupo $\mathrm{B}$. El grupo $\mathrm{C}$ no provocó cambios significativos en la mineralización de la superficie del esmalte. Se evidenciaron diferencias significativas entre el grupo $A$ bebidas gaseosas con el grupo $B$ jugos y néctares $(p=0,001)$ y con el grupo $C$ aguas minerales saborizadas y purificadas $(p=0,000)$, pero no se encontraron diferencias significativas entre el grupo $B$ y el grupo $C(p=0,528)$.

Tabla I. Capacidad tampón y pH inicial de las bebidas refrescantes analizadas. *Promedio de 3 repeticiones.

\begin{tabular}{lcc}
\hline Bebidas Refrescante & pH inicial \pm DS & pH final 0,005\% HCL \pm DS \\
\hline Coca-cola ${ }^{\circledR}$ & $2,08 \pm 0,2$ & $2,15 \pm 0,10$ \\
Coca-cola light ${ }^{\circledR}$ & $2,25 \pm 0,21$ & $2,17 \pm 0,09$ \\
Fanta ${ }^{\circledR}$ & $2,31 \pm 0,2$ & $2,17 \pm 0,09$ \\
Watts Manzana ${ }^{\circledR}$ & $2,49 \pm 0,18$ & $2,22 \pm 0,09$ \\
Andina Manzana ${ }^{\circledR}$ & $2,66 \pm 0,16$ & $2,26 \pm 0,07$ \\
Kapo Manzana ${ }^{\circledR}$ & $2,59 \pm 0,15$ & $2,22 \pm 0,06$ \\
Benedictino ${ }^{\circledR}$ & $3,10 \pm 0,27$ & $2,16 \pm 0,07$ \\
Vital® & $3,76 \pm 0,27$ & $2,16 \pm 0,08$ \\
Cachantun más ${ }^{\circledR}$ & $2,90 \pm 0,16$ & $2,30 \pm 0,07$ \\
\hline
\end{tabular}

Tabla II. Mineralización inicial, final y diferencia en cada una de las bebidas refrescantes. *Promedio de las muestras tras 3 mediciones.

\begin{tabular}{llccc}
\hline Bebidas Refrescantes & n & Mineralización inicial & Mineralización final & $\begin{array}{c}\text { Diferencia mineralización } \\
\text { X } \mathbf{n} \text { DS }\end{array}$ \\
\hline Coca-cola ${ }^{\circledR}$ & 5 & 2,87 & 16,86 & $13,10 \pm 5,23$ \\
Coca-cola light ${ }^{\circledR}$ & 5 & 2,86 & 13,93 & $11,06 \pm 3,11$ \\
Fanta ${ }^{\circledR}$ & 5 & 2,93 & 3,80 & $0,87 \pm 0,50$ \\
Watts manzana ${ }^{\circledR}$ & 5 & 2,86 & 4,86 & $2,00 \pm 1,31$ \\
Andina manzana ${ }^{\circledR}$ & 5 & 2,53 & 4,06 & $1,53 \pm 0,87$ \\
Kapo manzana ${ }^{\circledR}$ & 5 & 2,87 & 6,40 & $3,53 \pm 0,98$ \\
Benedict ino ${ }^{\circledR}$ & 5 & 2,73 & 3,00 & $0,27 \pm 0,43$ \\
Vital ${ }^{\circledR}$ & 5 & 2,80 & 2,93 & $0,13 \pm 0,69$ \\
Cachantun más ${ }^{\circledR}$ & 5 & 2,53 & 3,00 & $0,47 \pm 0,37$ \\
Control & 5 & 2,80 & 2,93 & $0,13 \pm 0,30$ \\
\hline
\end{tabular}




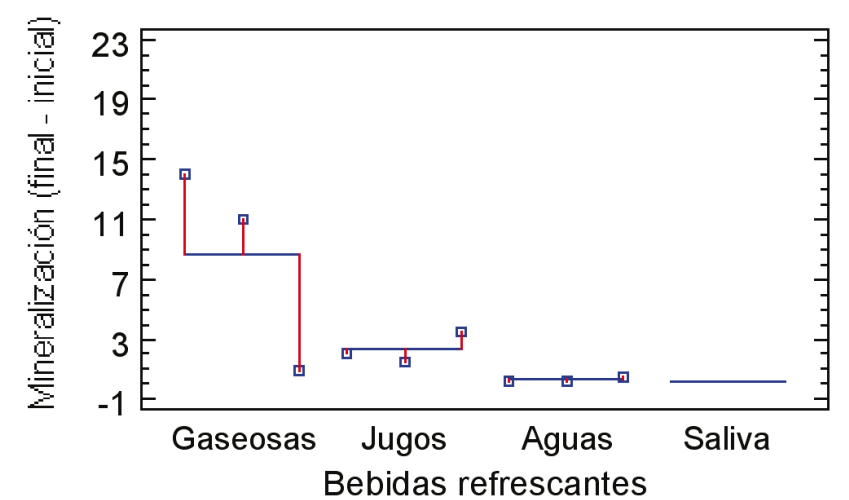

Fig. 1. Efecto de las distintas bebidas refrescantes según diferencia de mineralizaciones.

\section{DISCUSIÓN}

La Coca-cola $₫$ y Coca-cola light $₫$ fueron las bebidas refrescantes con menor $\mathrm{pH}(2,08)$ y $(2.25)$ respectivamente y las que produjeron un mayor efecto desmineralizador, esto se puede explicar ya que ambas presentan en su composición ácido fosfórico, el cual es un acidificante muy potente que interfiere con la absorción de calcio y contribuye al desequilibrio que lleva a una pérdida adicional de calcio (Tucker et al., 2007). Las bebidas gaseosas "de dieta", simplemente cambian el azúcar por edulcorantes no nutritivos, y que también son generadores de ácidos y pueden experimentar el riesgo de erosiones de esmalte. Esto se sabe a pesar de que los estudios sobre el rol de las bebidas gaseosas en la erosión dental, aún son preliminares (JADA).

TOTAL

GASEOSAS; AGUAS; JUGOS Y NECTARES; BEBIDAS PARA DEPORTISTAS; TE VENTAS PRIMER SEMESTRE 2000 - 2010 Millones de Litros y Tasas de Crecimiento

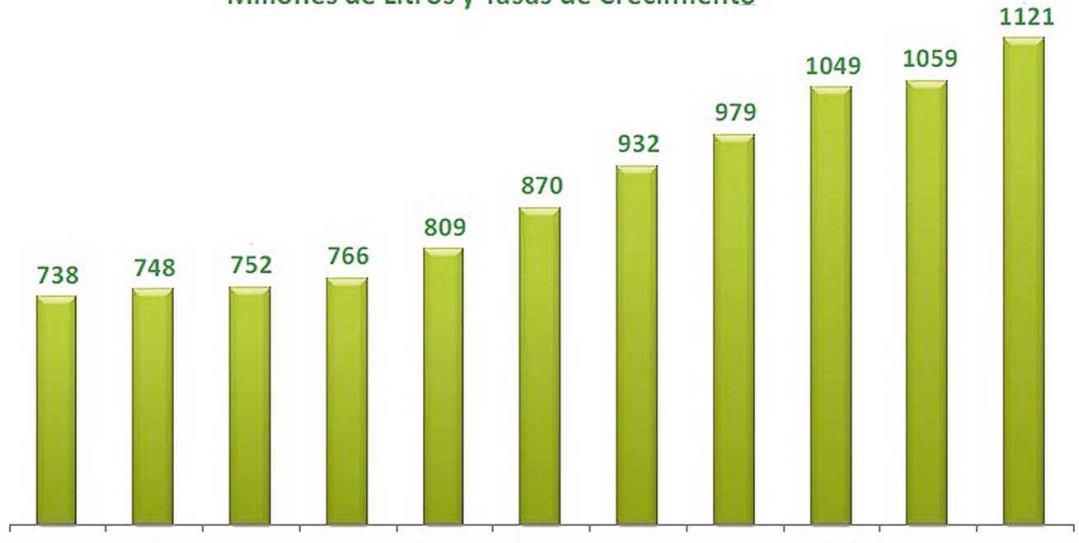

I Sem 2000 I Sem 2001 I Sem 2002 I Sem 2003 I Sem 2004 I Sem 2005 I Sem 2006 I Sem 2007 I Sem 2008 I Sem 2009 I Sem 2010 Fuente: Elaboración ANBER resultados ventas primer semestre 2000-2010

Fig. 2. Ventas primer semestre $2000-2010$ bebidas refrescantes.
Los resultados de este estudio demuestran que no todos los grupos de bebidas causan el mismo efecto, siendo las bebidas gaseosas las que producen mayor efecto sobre la mineralización de la superficie del esmalte dentario comparado con los jugos y néctares y las aguas minerales saborizadas y purificadas. Sin embargo, los jugos y néctares también causaron un efecto desmineralizador, superando el efecto de la bebida gaseosa Fanta $₫$, a pesar de que ésta presentaba menor $\mathrm{pH}(2,31)$ respecto a los jugos de manzana. Dentro de los jugos y néctares, el jugo Kapo $®$ fue el que provocó mayores efectos sobre la mineralización del esmalte, seguido por el Watts ${ }^{\circledR}$ de manzana y por último el jugo Andina $®$ manzana, estos jugos también tienen ácidos que son los que le otorgan las características refrescantes, de sabor y que actúan como preservantes y por consiguiente disminuyen el $\mathrm{pH}$ a la solución. En general, todas las bebidas refrescantes analizadas en este estudio tenían un $\mathrm{pH}$ menor a 4, y los procesos de desmineralización comienzan a ocurrir cuando el pH es menor a 5,5 que es el pH crítico de la hidroxiapatita (Featherstone et al.).

El proceso de desmineralización es altamente dependiente del grado de saturación de la solución desmineralizadora, del $\mathrm{pH}$, de la concentración de ácidos orgánicos no disociados, como también de la naturaleza de los ácidos orgánicos. Estas variables además determinarán la naturaleza de la lesión que se producirá en el esmalte (Margolis et al., 1999). Por tanto, las bebidas gaseosas y los jugos y néctares tienen el potencial para erosionar la superficie del esmalte en piezas dentarias debido a la cantidad de ácidos que presentan y la gran cantidad de azúcar que se le adiciona para neutralizar el sabor de los ácidos lo cual se encuentra relacionado con la aparición de caries (JADA). En la Figura 2, se muestra como ha aumentado el consumo de bebidas refrescantes en los últimos 10 años durante los primeros semestres. Es por esto, que se debe tener consciencia sobre los efectos erosivos a largo plazo de estos refrescos y enfatizar que la educación en salud debe partir desde la infancia para crear hábitos adecuados en alimentación, higiene oral y modificación temprana de malos hábitos (González et al., 2009). Uno de los factores más relevantes en la incidencia y prevalencia de la caries dental 
en niños es la falta de educación e información en salud oral por parte de las personas responsables de ellos: padres, tutores y/o profesores (Sarralde et al., 2008). Por lo general, son los padres y/o tutores los que se encargan de comprar estos refrescos a los que dan igual o mayor importancia que a otros bienes, siendo sólo superados por la carne y el pan. En la Tabla III, se muestra el gasto mensual y el consumo en litros según ingreso per cápita por familia en 10 grupos o deciles.

Como ya se ha mencionado, la condición erosiva que causan algunas de las bebidas refrescantes analizadas podría llevar a desarrollar a largo plazo un aumento de las caries dentales, siendo éste el mayor problema de salud bucodental en la mayoría de países industrializados, llegando a afectar entre el $70 \%$ y el $95 \%$ de la población escolar y adulta (OMS, 2002).

Tabla III. Gasto y consumo mensual de bebidas refrescantes según deciles.

\begin{tabular}{lcc}
\hline Deciles & $\begin{array}{c}\text { Gasto mensual por hogar } \\
\text { pesos agosto 2000 }\end{array}$ & $\begin{array}{c}\text { Consumo mensual por } \\
\text { hogar en litros }\end{array}$ \\
\hline 1 & 6.660 & 14,8 \\
2 & 7.902 & 17,5 \\
3 & 8.860 & 19.7 \\
4 & 9.850 & 21,9 \\
5 & 11.048 & 24,5 \\
6 & 12.405 & 27,5 \\
7 & 13.278 & 29,5 \\
8 & 13.756 & 30,5 \\
9 & 15.649 & 34,7 \\
10 & 14.272 & 31,7 \\
\hline Promedio & 11.657 & 25,9 \\
\hline
\end{tabular}

Fuente: Elaboración AMBER sobre la base de V Encuesta de Presupuestos Familiares.

\section{CONCLUSIONES}

El presente estudio mostró que existen diferencias significativas entre los efectos que producen las distintas bebidas sobre la mineralización de la superficie del esmalte. Se comprobó el potencial efecto erosivo de las bebidas gaseosas y de jugos y néctares mediante la variación de la mineralización, no así de las aguas minerales saborizadas y purificadas, las cuales no provocan cambios en la mineralización del esmalte de piezas dentarias. Se debe tener presente los efectos erosivos del consumo frecuente de bebidas con alto contenido de azúcar y de refrescos no nutritivos para así limitar su consumo.

MORENO R. X.; NARVÁEZ, C. C. G. \& BITTNER, S. V. In vitro effect of refreshing drinks on the mineralization of tooth enamel surface in extracted permanent dental pieces. Int. J. Odontostomat., 5(2):157-163, 2011.

ABSTRACT: The aim of this study was to determine the effect of refreshing drinks on the mineralization of tooth enamel surface in extracted permanent dental pieces. For this an experimental study was conducted where the sample was composed by 50 permanent premolars extracted as an entire piece. These pieces were randomly distributed in three study groups: soft drinks, juices and nectars, and purified and flavored mineral waters, in addition to a control group. The teeth were carefully washed and stored in artificial saliva at $4^{\circ} \mathrm{C}$. Before starting the exposure to refreshing drinks, all dental slices were tested in order to measure their baseline mineralization using the Diagnodent 2095 equipment (Kavo®). The exposition consisted in one minute of contact with the drink corresponding to each group, followed of three minutes in artificial saliva. This cycle was repeated 5 times in 20 minutes time. This procedure was carried out once daily, for one month, and every day new refreshing drinks were used. Once the assay finished, the premolar mineralization was measured again, in order to make comparisons between groups. The soft drinks group caused the highest demineralization on the teeth enamel surface $(p=0.000)$, followed by the juices and nectars group $(p=0.000)$. In the purified and flavored mineral waters group, no effects were found on the mineralization of the enamel surface. A demineralizing effect on the enamel surface of dental pieces was observed only in the groups of soft drinks and juices, where Coca-Cola ${ }^{\circledR}$ caused the highest effect, followed by Coca-Cola light $₫$ and then $\mathrm{Kapo} \circledast$.

KEY WORDS: erosion, enamel, mineralization, demineralization, soft drinks, diagnodent. 


\section{REFERENCIAS BIBLIOGRAFICAS}

Carvalho, S.; Magalhães, A.; de Andrade, M. \& Buzalaf, M. Evaluation of the erosive potential of soft drinks. Eur. J. Dent., 1:10-3, 2007.

Featherstone, J. D.; Behrman, J. M. \& Bell, J. E. Effect of whole saliva components on enamel demineralization in vitro. Crit. Rev. Oral Biol. Med., 4(3-4):357-62, 1993.

González, S.; Álvarez, L.; Bustamante, A.; Atuesta, C.; Betancur, G.; Maya, D. \& Múnera, T. Promoción y prevención en salud bucal en docentes y escolares de una escuela de Medellín. Rev. Colomb. Investig. Odontol., 1(1):46-57, 2009.

JADA. Diet and tooth decay. JADA, 133:527, 2002.

Kavo DIAGNOdent. Diagnóstico de caries y cómo utilizar el sistema DIAGNOdent. Biberach: Kavo. Dental Excellence, 2002.

Liñan, C.; Meneses, A. \& Delgado, L. Evaluación in vitro del efecto erosivo de tres bebidas carbonatadas sobre la superficie del esmalte dental. Rev. Estomatol. Herediana., 17(2):58-62, 2007.

López, O. \& Cerezo, M. Potencial erosivo de las bebidas industriales sobre el esmalte dental. Rev. Cubana Salud Pública., 34(4):1-9, 2008.

Margolis, H. C.; Zhang, Y. P.; Lee, C. Y.; Kent, R. L. Jr. \& Moreno, E. C. Kinetics of enamel demineralization in vitro. J. Dent. Res., 78(7):1326-35, 1999.

Mas, L. A. C. Efecto erosivo valorado a través de la microdureza superficial del esmalte dentario, producido por tres bebidas industrializadas de alto consumo en la ciudad de Lima, estudio in vitro. Tesis (Cirujano Dentista). Universidad Nacional Mayor de San Marcos, Lima, 2002.

Narváez C. Bases bioquímicas de los procesos de mineralización y desmineralización en el esmalte dental. En: Elementos de bioquímica para Odontología. Narváez. C. $1^{\text {a }}$ ed. Chile, Editorial Nuevo Ser, 2008. pp.115-31.

Owens, B. \& Kitchens, M. The Erosive potencial of soft a drinks on enamel surface substrate: an in vitro scanning electron microscopy investigation. J. Contemp. Dent. Pract., 8(7):11-20, 2007.

Sarralde, D. A.; Lamby, T. C. \& Rivera, R. M. Programa de educación en salud oral en escolares de 5 a 6 años de edad para la prevención de caries de dientes permanentes. Rev. Fed. Odontol. Colomb., 71(222): 8-16, 2008.

Servicio de información y noticias científicas. (2009). Disponible en: http://www.plataformasinc.es/ index.php/es//Noticias/Un-consumo-excesivo-debebidas-de-cola-provoca-enormes-problemasmusculares

Tucker, K. L.; Morita, K.; Qiao, N.; Hannan, M. T.; Cupples, A. \& Kiel, D. P. Los refrescos de cola, pero no otras bebidas carbonatadas, se relacionan con baja densidad mineral ósea en mujeres ancianas: estudio de osteoporosis Framingham*. Revista del Climaterio, 10(56):50-9, 2007.

World Health Organization (WHO). Global oral health data bank. Geneva, World Health Organization, 2002.

Zero, D. T. \& Lussi, A. Erosion--chemical and biological factors of importance to the dental practitioner. Int. Dent. J., 55(4 Suppl 1):285-90, 2005.

Dirección para correspondencia:

Ximena Moreno Ruiz

Facultad de Odontología

Universidad del Desarrollo

Concepción

CHILE

E-mail:ximemr@gmail.com

Recibido : 03-07-2011

Aceptado: 28-07-2011 